
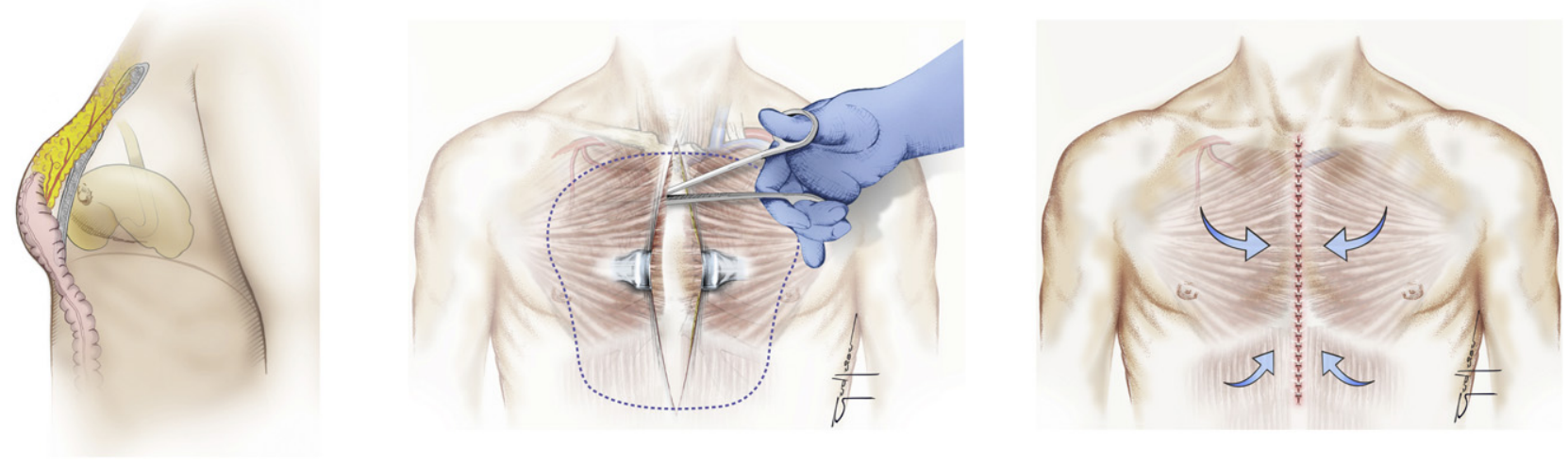

FIGURE 2. Surgical approach.

\section{References}

1. Losanoff JE, Richman BW, Jones JW. Disruption and infection of median sternotomy: a comprehensive review. Eur J Cardiothorac Surg. 2002;21:831-9.

2. Wettstein R, Erni D, Berdat P, Rothenfluh D, Banic A. Radical sternectomy and primary musculocutaneous flap reconstruction to control sternal osteitis. J Thorac Cardiovasc Surg. 2002;123:1185-90.
3. Roh TS, Lee WJ, Lew DH, Tark KC. Pectoralis major-rectus abdominis bipedicled muscle flap in the treatment of poststernotomy mediastinitis. J Thorac Cardiovasc Surg. 2008;136:618-22.

4. Ramirez OM, Ramasastry SS, Granick MS, Pang D, Futrell JW. A new surgical approach to closure of large lumbosacral meningomyelocele defects. Plast Reconstr Surg. 1987;80:799-809.

\title{
Coronary artery thromboembolism as a result of left ventricular sump aneurysm after congenital heart surgery
}

Timothy B. Cotts, MD, ${ }^{\mathrm{a}, \mathrm{b}}$ Felix J. Rogers, DO, ${ }^{\mathrm{d}}$ Gisela C. Mueller, MD, ${ }^{\mathrm{c}}$ and Sharlene M. Day, MD, ${ }^{\mathrm{b}}$ Ann Arbor and Trenton, Mich

Placement of a sump drain to vent the left ventricle during cardiac surgery often leaves a small apical aneurysm, which is generally considered to be a harmless remnant. We report the first case of a thromboembolic complication from

From the Departments of Pediatrics, ${ }^{\mathrm{a}}$ Internal Medicine, ${ }^{\mathrm{b}}$ and Radiology, ${ }^{\mathrm{c}}$ University of Michigan Hospitals, Ann Arbor, Mich; and Department of Internal Medicine, ${ }^{\mathrm{d}}$ Oakwood Southshore Medical Center, Trenton, Mich.

Disclosures: Authors have nothing to disclose with regard to commercial support. Received for publication July 5, 2012; accepted for publication Aug 14, 2012; available ahead of print Sept 10, 2012.

Address for reprints: Sharlene M. Day, MD, 1150 W Medical Center Dr, 7301 MSRB III, Ann Arbor, MI 48109 (E-mail: sday@umich.edu)

J Thorac Cardiovasc Surg 2012;144:e119-21

$0022-5223 / \$ 36.00$

Copyright (C) 2012 by The American Association for Thoracic Surgery

http://dx.doi.org/10.1016/j.jtcvs.2012.08.035

a sump aneurysm in an adult man 41 years after ventricular septal defect repair.

\section{CLINICAL SUMMARY}

A 46-year-old man with a history of a ventricular septal defect repair in 1968 presented with intermittent chest discomfort of approximately 4 weeks duration. The episodes were infrequent and nonexertional but were characterized by gripping tightness in the upper anterior chest. One month earlier, he had a sudden witnessed event in which he lost feeling on his right side and collapsed with loss of control of his right arm and leg. The episode lasted for 1 minute with spontaneous resolution, and the patient did not seek medical attention. He was not taking any medications at the time of presentation. Family history was notable for sudden cardiac death in a brother at age 39 years, whose autopsy showed coronary artery disease as the cause of death. His mother died of a myocardial infarction at age 62 years, and his father had coronary bypass surgery at age 60 and is alive at 74 years of age. 

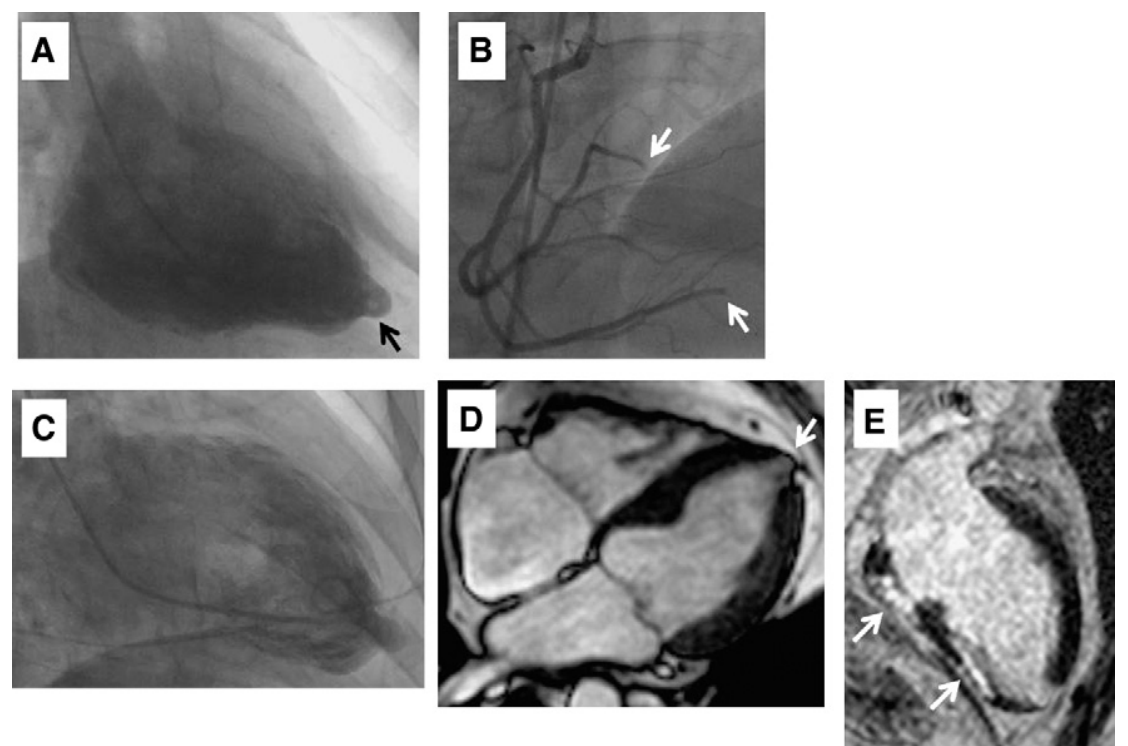

FIGURE 1. A, Left ventriculogram from initial catheterization showing LV apical aneurysm with filling defect (arrow). B, Injection of right coronary artery 5 months later at the time of presentation with inferior ST-elevation myocardial infarction. Arrows indicate abrupt occlusion of posterior descending and posterior lateral arteries. C, Left ventriculogram showing persistence of LV apical aneurysm, but without the filling defect seen previously. D, Cardiac magnetic resonance imaging shows a small apical aneurysm (arrow) characteristic of a remnant from a sump used to vent the left ventricle during surgery. E, Transmural late gadolinium uptake in 2 discrete areas corresponding to infarct territories (arrows).

On physical examination at initial presentation, the patient's blood pressure was $122 / 64 \mathrm{~mm} \mathrm{Hg}$, height was 5'9', weight was $208 \mathrm{lbs}$, and body mass index was 30.7 $\mathrm{kg} / \mathrm{m}^{2}$. Examination of the pulmonary and cardiovascular systems showed normal results.

A standard treadmill exercise stress test showed 1-mm horizontal ST-segment depression in V6 and borderline 1-mm ST-segment elevation in V4R. Myocardial perfusion images showed a fixed inferior defect. He underwent cardiac catheterization that demonstrated normal coronary arteries. There were no discrete wall motion abnormalities on the left ventriculogram, and systolic function was normal. However, a small apical aneurysm containing a radiolucent filling defect was visualized (Figure 1, $A$ ). The cause of this aneurysm was not readily apparent at the time.

Five months later, the patient presented with an inferior ST-elevation myocardial infarction associated with abrupt thrombotic occlusion of the posterior lateral and posterior descending arteries (Figure 1, B, and Video 1). The filling defect in the apical aneurysm was not seen (Figure 1,C). He underwent primary angioplasty and was anticoagulated with warfarin for a presumed thromboembolic event. Cardiac magnetic resonance imaging revealed a small apical aneurysm characteristic of a remnant from a sump used to vent the left ventricle during surgery (Figure 1, D, and Video 2). There were 2 discrete areas of transmural delayed gadolinium enhancement corresponding to the infarct territories
(Figure 1, E). The ventricular cavities were not dilated or hypertrophied. Left ventricular (LV) systolic function was mildly depressed with an ejection fraction of $44 \%$.

\section{DISCUSSION}

In the early era of cardiac surgery, sump drains were routinely placed in the LV apex. Such drains were subsequently replaced with cannulae placed in the right upper pulmonary vein, which then crossed the mitral valve and extended into the LV apex. Apical aneurysms are a common occurrence after placement of sump drains, present in as many as one third of patients after surgery for congenital heart disease. ${ }^{1}$ The size of these aneurysms is generally small and not determined by the type of cardiac defect, postoperative LV pressures, age at time of surgery, or duration of follow-up. In contrast with congenital LV aneurysms or diverticula, in which complications of ventricular arrhythmias, rupture, and thromboembolism have been reported, ${ }^{2,3}$ sump aneurysms have generally been regarded as innocuous, with only rare reports of ventricular arrhythmias. ${ }^{4}$

We report the first recognized case of a thromboembolic event in a patient with a sump aneurysm. The serendipitous finding of a filling defect in the aneurysm 5 months before the thrombotic myocardial infarction, not present at the time of infarction, provides support for the aneurysm being the source of thromboembolism. An echocardiogram did not demonstrate an intracardiac shunt, 
although a transesophageal echocardiogram with agitated saline contrast was not performed to completely rule out a patent foramen ovale with an intermittent right to left shunt.

It was assumed that this aneurysm was related to a sump drain placed at the time of surgery. This would have been common practice in the surgical era during which the patient's ventricular septal defect was repaired. Unfortunately, the hospital where the patient underwent surgery no longer exists, and operative notes were not available for review. It is possible that the LV aneurysm was congenital, because a significant proportion $(26 \%)$ of congenital LV aneurysms reported in the literature have been associated with ventricular septal defect. ${ }^{5}$ However, in this patient, the size and location of the defect were most consistent with an LV sump aneurysm.

\section{CONCLUSIONS}

This case supports consideration of a sump aneurysm as a potential source of thromboembolism in a patient with prior surgical correction of a congenital heart defect.

\section{References}

1. Weesner KM, Byrum C, Rosenthal A. Left ventricular aneurysms associated with intraoperative venting of the cardiac apex in children. Am Heart J. 1981;101: 622-5.

2. Ohlow MA, Secknus MA, Geller JC, von Korn H, Lauer B. Prevalence and outcome of congenital left ventricular aneurysms and diverticula in an adult population. Cardiology. 2009;112:287-93.

3. Haegeli LM, Ercin E, Wolber T, Brunckhorst C, Tanner FC, Jenni R, et al. Arrhythmic manifestations in patients with congenital left ventricular aneurysms and diverticula. Am J Cardiol. 2011;108:1826-30

4. Weesner KM, Byrum CJ, Dick M, Rocchini AP, Behrendt DM, Hees P. Ventricula tachycardia associated with a left ventricular apex sump aneurysm in an adolescent. Am Heart J. 1983;105:334-6.

5. Ohlow MA. Congenital left ventricular aneurysms and diverticula: definition, pathophysiology, clinical relevance and treatment. Cardiology. 2006;106: 63-72.

\title{
Delayed presentation of aortic laceration from seventh rib fracture: An uncommon complication
}

\author{
Riley Kitamura, BA, ${ }^{a}$ Modesto Colon, MD, ${ }^{a}$ and Jasmine Dave, MD, ${ }^{\mathrm{b}}$ New York, NY
}

Rib fractures are common in blunt trauma and markers of the severity and multisystem scope of the injury. Traumatic aortic injury is a leading cause of mortality, with the majority of cases involving violent deceleration injuries that result in aortic rupture and immediate death; only $15 \%$ of patients with blunt aortic injury arrive at the hospital alive. ${ }^{1,2}$ Traumatic injury to the aorta by a fractured rib is rare yet also threatens the life of the patient. We report a patient with descending aortic laceration from a traumatic rib fracture who presented 2 days after the initial trauma.

\section{CLINICAL SUMMARY}

A 63-year-old man was admitted after a 30-foot fall. A computed tomography (CT) scan demonstrated a left

\footnotetext{
From the Mt Sinai School of Medicine, ${ }^{\mathrm{a}}$ New York, NY; and Division of General Surgery, ${ }^{b}$ Department of Surgery, Mt Sinai School of Medicine, Elmhurst Hospital Center, New York, NY

Disclosures: Authors have nothing to disclose with regard to commercial support.

Received for publication June 6, 2012; revisions received Aug 1, 2012; accepted for publication Aug 14, 2012; available ahead of print Sept 10, 2012.

Address for reprints: Jasmine Dave, MD, Division of General Surgery, Elmhurst Memorial Hospital, 79-01 Broadway, Elmhurst, NY 11373 (E-mail: davej@ nychhc.org).

J Thorac Cardiovasc Surg 2012;144:e121-3

0022-5223/\$36.00

Copyright (c) 2012 by The American Association for Thoracic Surgery

http://dx.doi.org/10.1016/j.jtcvs.2012.08.036
}

hemothorax and pneumothorax and left flail chest with posterior-medial fractures of ribs 5 to 11 . The fractured posterior tip of the seventh rib was angled anteriorly resting approximately $5 \mathrm{~mm}$ from an unremarkable descending aorta in CT 3-dimensional reconstructions (Figure 1). There was no extravasation of contrast on the CT scan. Additional injuries were transverse process fractures of thoracic vertebrae 10 and 12 and lumbar vertebrae 1 to 5 , spinous process fracture of lumbar vertebrae 1 to 3 , and left renal parenchyma contusion.

The patient underwent insertion of an intercostal chest drain with $500 \mathrm{~mL}$ of sanguineous output. A subsequent chest roentogram was negative for residual hemothorax. The patient remained stable until the morning of hospital day 2. At that time, a sudden output of 2.5 liters of blood from the chest drain was noted. The patient was immediately taken to the operating room. Because the CT scan demonstrated an uninjured aorta, initial exploration began with video-assisted thoracoscopy. Exploration evacuated 1.5 liters of blood and noted the posterior fractured tip of the seventh rib abutting a small clot covering the aortic adventitia. A left posterolateral thoracotomy was performed, and a 4-mm puncture wound in the descending aorta adjacent to the seventh rib was noted. There was no evidence of aortic dissection or intramural hematoma, and the aorta 